\title{
A psychotherapeutic computer application: Modification of technological competence
}

\author{
DEBRA NEUMANN \\ The Catholic University of America, Washington, D.C.
}

\begin{abstract}
The increasing sophistication of computer technology, combined with increased specification of therapeutic interventions, has facilitated development of computer programs that have achieved marked success in the psychotherapeutic treatment of circumscribed populations. This paper briefly reviews the history of computerized psychotherapy and examines several successful therapeutic computer applications in depth. These applications have attempted to replace the therapist with a computer. Another possible, as yet unexplored, application is the use of the computer as a vehicle for modification of an individual's perceived competence to effectively operate on his or her environment. Using a computer to successfully manipulate one's environment can provide a personal mastery experience that has the potential to contribute significantly to an increase in perceived self-competence, an essential component of positive therapeutic change. A study that would provide empirical support for this type of computer application is proposed.
\end{abstract}

In 1965, Joseph Weizenbaum developed a computer program called ELIZA which was based on a model of a specific type of natural language communication between two adults-the model of Rogerian psychotherapy. ELIZA permitted a limited type of natural language communication between human and computer by restating information received from its user's input and forming openended questions based upon that information. Thus the computer sounded very much like a client-centered therapist. Soon thereafter, Colby, Watt, and Gilbert (1966) published a preliminary report announcing the creation of a computer program which operated on the same model as ELIZA and which they hoped would be capable of genuine psychotherapeutic intervention. Computer therapy was thought to be possible because, like the computer, a therapist was assumed to be an information processor and decision maker whose role was to build a cognitive model of his or her client, make inferences based on that model, and then decide what should be communicated to the client.

A typical human-computer therapeutic interaction between a young woman and a computer programmed to communicate according to the Rogerian paradigm can be found in Appendix A. This excerpt typifies computer therapy applications of the mid-60s, when hopes for development of computer programs that would act as "talk" therapists ran high in certain circles.

Twenty years later, we find that no successful programs of this sort have been developed. The flexibility required to deal with the many contextual clues so important to successful therapy has proved to be elusive. The programs themselves have been difficult to develop, and interac-

The author's mailing address is: 1021 Woodside Parkway, Silver Spring, MD 20910. tions of the type cited have proven frustrating to clients. These difficulties have been greeted with relief by many (e.g., Spero, 1978; Weizenbaum, 1976).

Although computers have not replaced talk therapists, they have served a second important function foreseen by Colby et al. (1966), who suggested that computers could be programmed to serve as unique tools in the application of specific therapeutic techniques. Over the past 20 years, largely due to the development of structured, shortterm behavioral interventions, the use of computers in this capacity has begun to take root. For example, computer intervention has been implemented successfully as an aid to language development in nonspeaking children (Colby, 1968), in desensitization training (Lang, Melamed, \& Hart, 1970), in the treatment of test anxiety (Biglan, Villwock, \& Wick, 1979), in the treatment of aphasic subjects with writing disorders (Seron, Deloche, Moulard, \& Rousselle, 1980), and in cognitive-behavioral counseling (Selmi, Klein, Greist, Johnson, \& Harris, 1982; Wagman, 1980; Wagman \& Kerber, 1980).

A closer look at the cognitive-behavioral interventions will provide a "state-of-the-art" view of the field today and give insights into further applications. Wagman (1980) developed the PLATO DCS (Dilemma Counseling System) program at the University of Illinois, ChampaignUrbana. By monitoring input, providing feedback, and suggesting solutions based on references to stored data, the computer provides clients with a self-paced method for solving a current psychological dilemma of the avoidance-avoidance type, while at the same time providing instruction generalizable to future dilemmas.

Wagman tested the effectiveness of his program with 77 undergraduate students who reported significant dilemmas. Forty-one students were assigned to an experi mental PLATO DCS group. These subjects met with the computer for two counseling sessions. After the second 
session they were asked to rate the adequacy of the best solution to their dilemma arrived at with PLATO DCS aid. They were also asked to complete a nine-page questionnaire evaluating DCS according to the following criteria: (1) Did they personally accept computer therapy? (2) Was DCS an effective teacher? (3) Was DCS an effective counselor? Ninety percent of the students felt that DCS had helped them find a solution to their dilemmas (21\% found it "extremely helpful," $69 \%$ "somewhat helpful," and only $10 \%$ "not at all helpful"). Fifty-six percent of the participants stated that DCS was "not too impersonal." However, 64\% reported that they would prefer to use DCS as an adjunct while seeing a human counselor.

The 36 remaining subjects served as a no-DCSinteraction control group. They did not meet with DCS but did participate in the follow-up sessions. (Solutions to their dilemmas were credited to spontaneous remission.) The experimental group members showed significantly greater reduction in anxiety caused by their reported dilemmas as compared to control group members at a 1-week follow-up.

Wagman concluded that cognitive counseling provides an effective match between client need and computer capability and that future applications in the area of cognitive therapy techniques should be attempted. Unfortunately, Wagman's experimental design had several flaws, among them the fact that he did not include a group to control for placebo effects (i.e., there was no group that used a computer for a nontherapeutic task). Nor does the homogeneity of his sample reveal much about how DCS would be accepted by society at large, given that college students are probably more open to accepting advances in technology than the average person. From his work, we can state that some form of working with a computer seems to aid college students in their resolution of personal dilemmas and that future study is warranted. An example of human-computer interaction via PLATO DCS is found in Appendix B.

In another innovative application, Selmi et al. (1982) developed MORTON, a computer program which provides cognitive-behavioral therapy to depressed individuals. They chose cognitive-behavioral therapy for treatment of depression by computer because the cognitive approach employs a short-term, well-defined treatment strategy that is directive (i.e., it does not involve unguided dialogue between therapist and client and thus avoids the difficulties faced by talk therapy). In their 1982 article, Selmi et al. proposed to test MORTON experimentally on mildly to moderately depressed nonpsychotic volunteer subjects. Results of this study have not been published to date. A typical format for six sessions with MORTON can be found in Appendix C.

Although there is no empirical confirmation, one can envision several advantages of the use of computers in cognitive therapy with depressed clients. (1) It provides savings of time for both client and therapist. Beck, Rush, Shaw, and Emery (1979) developed an agenda for cogni- tive treatment of depression which calls for up to 20 sessions over up to 12 weeks, whereas MORTON requires only 6 to 8 sessions over 6 weeks. (2) The computer therapist provides greater experimental control over interpersonal variables in therapy (e.g., the computer does not get bored, angry, or tired). (3) MORTON is more available than any individual therapist could be, providing maximum convenience to the client. Given a computer and a free terminal, therapy can take place anytime, anywhere.

In contrast to the two approaches described above, in which the computer was programmed to function in the role of a human therapist employing a specific technique, Colby (1968) used the computer as a computer by developing computer games to aid language development in nonspeaking children. In a typical game, a child sits at a computer terminal and selects any letter key he or she chooses. The corresponding letter appears on the terminal and a voice on tape pronounces it. Subsequently, a word beginning with the selected letter appears (the words chosen to illustrate pronunciation are tailored to fit the child) and is pronounced as that letter is highlighted. The child is instructed to repeat the highlighted word and then to select another key. For example, when a girl who loves pretzels presses the $p$ key, she will see the word pretzel displayed along with a picture of a pretzel and the letter $p$. Concurrently, she will hear the word pronounced and be encouraged to repeat the word.

Colby tested this approach with a heterogeneous group of 10 nonspeaking children ranging in age from 3 to 12 years. Besides having differing diagnoses, all the children were in varying concomitant treatments. Colby judged that 8 of them improved after working with the computer. (Improvement was measured as an increase in the number of words that the child was able to use appropriately after training.) Obviously, no experimental design was employed and the results are difficult to interpret. However, from his case studies Colby concluded that there is something about the experience of playing with a computer that "excites and interests both normal and disturbed children"' (p. 650).

The specific applications examined above show that computer-assisted cognitive-behavioral psychotherapy is possible with a clientele consisting of normal to mildly disturbed college students and may be applicable to more disturbed, depressed individuals. Colby's (1968) work has shown that the computer has potential as an adjunct to therapy. I propose an innovative use of the computer as a therapeutic tool that can be used as an adjunct to therapy aimed at modification of an individual's self-concept. Before describing such an application, it is necessary to develop its conceptual basis.

The ability to effectively manipulate one's environment has long been acknowledged as crucial to the development of an adequate self-concept. White (1959) attributed this to an aspect of motivation which he called "effectance motivation." According to White's model, each organism is born with an intrinsic desire to produce some type of effect on its environment. If these attempts meet 
with success, they result in heightened feelings of efficacy and inherent pleasure. Erikson (1963) stated that the mastery of an object outside oneself (which he called a "physical mastery experience") provides the individual with pleasure and, if the mastery is valued by one's culture, is a source of social esteem. In short, these developmental and motivational models posit that successful mastery gives rise to a heightened sense of competence. Bandura (1977) stated that all positive behavioral change can be viewed as a result of an increased sense of one's own efficacy.

If these theorists are correct, it is reasonable to infer that the experience of manipulating one's environment via a computer may have value in that it causes an individual to view himself or herself as more competent. The computer can provide individuals with opportunities to confront and master situations that are optimally challenging and are highly valued by our culture. The latter two components must be part of any experience in order for it to result in a sense of heightened efficacy. This increased sense of efficacy will be reflected in immediate feelings of pleasure and confidence that one would be successful in a future encounter with the computer. Bandura (1977) stated that this increase in perceived competence has the potential to influence the initiation and persistence of coping behaviors. Therefore, I posit that computer mastery experiences may contribute to positive behavioral change.

One way to test empirically the value of using a computer as a mediator of efficacy expectations is to provide individuals with potential mastery experiences on a computer.

Will effective task performance raise a person's conviction that he or she can successfully carry out the action needed to produce a similar effect in the future? Will it also provide a sense of pleasure? In order to answer these questions, I will conduct the following study. Subjects will be recruited from the Catholic University of America Psychology Department's subject pool. All potential subjects will be screened for previous computer experience by completion of the Computer Experience Questionnaire (Heinssen, Glass, \& Knight, 1984), and only those who have never used a computer or who have had only limited computer experience (e.g., have played computer games at a video arcade or have used a computer printout done by someone else) will be included as subjects in the study. Individuals who qualify and agree to participate will be randomly assigned to one of three groups: an experimental group, in which a mastery experience on a computer will be provided, and two control groups-one in which subjects will read a short story on a computer terminal (to control for non-mastery-related computer effects) and one in which subjects will simply read a short story out of a book (to control for attentionplacebo effects).

Immediately prior to using the computer, subjects will complete the following pretest measures: the Multidimen- sional Locus of Control Scale (Levenson, 1973), the SelfReport Inventory II (O'Brien \& Epstein, 1974), and the Differential Emotions Scale (Izard \& Caplan, 1974), an assessment of 10 discrete emotional states. Levenson's Multidimensional Locus of Control Scale comprises three subscales. Its "internal" scale measures "personal mastery" - an assessment of generalized ability to cope with the outside world. The Self-Report Inventory II consists of nine scales that measure various aspects of selfesteem and competence.

In addition, the experimental group will be asked to complete an efficacy and outcome expectancy questionnaire. This questionnaire will be task specific and will assess a subject's expectancies about his or her perceived ability to perform a hierarchy of discrete computer tasks (e.g., "I will be able to X"), his or her expectancies about the result of completing these tasks (e.g., "Behavior X will lead to outcome $Y$ "), and the value to the subject of the outcome of successful task completion.

The subjects will then be escorted into a private room. Subjects in the mastery task group will use an IBM PC to accomplish a task such as one provided by readily available software which challenges the user to manipulate a frog to its destination-a "great pink lily pad" in the center of the pond-by causing the frog to jump from lily pad to lily pad. Mastery group subjects will be told that they may spend up to $20 \mathrm{~min}$ on the computer, but will be free to quit the task at any time.

Control group subjects will be ushered to the same room. Computer-read group subjects will find a short story displayed on the computer monitor. They will be shown how to use the "page down" key and instructed to read the story. Book-read subjects will be given the same short story to read from a book.

After each subject who uses the computer, either for the manipulative task or for reading, has completed the computer session, he or she will complete the Computer Attitude Scale (Loyd \& Gressard, 1984), which comprises three subscales: a computer anxiety scale, to assess undesirable consequences of the computer experience; a computer liking scale, to assess enjoyment of the experience; and a computer confidence scale, to assess confidence in ability to learn more about computers or to use them again. The subjects will also be asked to fill out another Differential Emotions Scale, as will the control group members who read from a book.

Data analysis will be undertaken to determine the differences within and between groups on affect before and after the experimental manipulation and on attitudes toward future computer use. The relationship between task challenge (as assessed on the efficacy questionnaire), successful mastery of the task, and degree of pleasure experienced will also be examined. It is predicted that experimental group subjects who view the task as challenging and who successfully complete it will have 
significantly elevated scores on the DES interest, joy, and surprise scales and will express confidence in their ability to use the computer again.

Such results would bode well for further exploration of the use of computers as adjuncts in those therapeutic processes whose goals are to increase a client's sense of efficacy and improve his or her self-concept.

An additional contribution of this study will be further specification of the components of the competence construct. Harter (1978) identified cognitive (academic, problem-solving capabilities), physical (athletic ability), and social (interpersonal skills) components. The component to be tested in this study does not fit easily within any of these groups. Rather, it seems to be a component that could be called technological efficacy, perceived competence when faced with modern technology. The study will aid in the operationalization and testing of this proposed component.

The proposed study will also permit the generation of hypotheses about the effects of failure experiences on technological competence and will aid in the determination of what balance of success and failure is required to produce an optimal positive change in effectance motivation.

In addition, attention to correlates of perceived competence/self-esteem and perception of control (mediating variables of the mastery experience) will serve to verify the prediction that subjects who score low on the internal locus of control scale, low on the self-esteem scale, and low in efficacy expectations prior to using the computer should show especially marked improvement in affect and confidence afterward. Further study of these correlations will provide essential guidelines for the selection of individuals for whom computer use will be most effective.

The issue of perhaps greatest import to the future application of computer technology as a vehicle for behavioral change concerns the degree to which modification of a specific component of perceived competence will affect other components, as well as one's global sense of competence. Bandura, Jeffrey, and Gajdos (1975) claimed that the sense of competence that arises out of a single personal mastery experience is generalizable to other situations in which the client's performance has been hindered by a sense of personal inadequacy. If it can be empirically demonstrated that a heightened sense of efficacy resulting from computer use generalizes to perceived competence in the social, cognitive, and physical spheres, the value of such computer experiences in bringing about behavioral change will rise markedly.

The possibility of using computers with a wide range of nonnormal (paranoid, avoidant, masochistic, depressed, and psychotic) adults and children under varying task conditions will require further investigation. Preliminary support for this possibility is offered by Greist et al. (1973), who, in a study of suicidal hospital emergency room "walk-ins," concluded that a majority of these severely disturbed individuals found using the computer to complete an initial intake interview to be an egoorienting experience.
The computer is a flexible, consistent, and economical tool. If future studies demonstrate its effectiveness in the modification of an individual's perceived competence, the computer will be in a position to play a unique role as an adjunct to comprehensive, multimodal, and eclectic treatment plans.

\section{REFERENCES}

Bandura, A. (1977). Self-efficacy: Toward a unifying theory of behavioral change. Psychological Review, 84, 191-215.

Bandura, A., JefFrey, R. W., \& Gajdos, E. (1975). Generalizing change through participant modeling with self-directed mastery. $B e$ haviour Research \& Therapy, 13, 141-152.

Beck, A. T., Rush, A. J., Shaw, B. F., \& Emery, G. (1979). Cognitive therapy of depression. New York: Guilford Press.

Biglan, A., Villwock, C., \& Wick, S. (1979). The feasibility of a computer-controlled program for the treatment of test anxiety. Journal of Behavioral Therapy \& Experimental Psychiatry, 10, 47-49.

CoLBY, K. M. (1968). Computer-aided language development in nonspeaking children. Archives of General Psychiatry, 19, 641-651.

Colby, K. M., Watt, J. B., \& Gilbert, J. P. (1966). A computer method of psychotherapy: Preliminary communication. Journal of Nervous \& Mental Disease, 142, 148-152.

ErIKSon, E. H. (1963). Childhood and society (2nd ed.). New York: Norton.

Greist, J. H., Gustafson, D. H., Strauss, F. F., Rowse, G. L., Laughren, T. P., \& Chiles, J. A. (1973). A computer interview for suicide-risk prevention. American Journal of Psychiatry, 130, 1327-1332.

HaRTER, S. (1978). Effectance motivation reconsidered: Toward a developmental model. Human Development, 21, 34-64.

Heinssen, R. K., Glass, C. R., \& Knight, L. A. (1984, November). Assessment of computer anxiety: The dark side of the computer revolution. Paper presented at the meeting of the Association of Advancement of Behavior Therapy. Philadelphia, PA.

IZARD, C. E., \& Caplan, S. (1974). Sex differences in emotional responses to erotic literature. Journal of Consulting \& Clinical Psychology, 42, 468

Lang, P. J., Melamed, B. G., \& Hart, J. (1970). A psychophysiological analysis of fear modification using an automated desensitization procedure. Journal of Abnormal Psychology, 76, 220-234.

LEVENSON, H. (1973). Multidimensional locus of control in psychiatric patients. Journal of Consulting \& Clinical Psychology, 41, 397-404.

LOYD, B. H., \& GRESSARD, C. (1984). Reliability and factorial validity of computer attitude scales. Educational \& Psychological Measurement, 44, 501-505.

O'Brien, E. J., \& EPSTEIN, S. (1974, August). Naturally occurring changes in self-esteem. Paper presented at the annual meeting of the American Psychological Association, New Orleans, LA.

Selmi, P. M., Klein, M. H., Greist, J. H., Johnson, J. H., \& HarRis, W. G. (1982). An investigation of computer-assisted cognitivebehavior therapy in the treatment of depression. Behavior Research Methods \& Instrumentation, 14, 181-185.

Seron, X., Deloche, G., Moulard, G., \& Rousselle, M. (1980). A computer-based therapy for the treatment of aphasic subjects with writing disorders. Joumal of Speech \& Hearing Disorders, 45, 45-48.

SPERo, M. H. (1978). Thoughts on computerized psychotherapy. Psychiatry, 41, 279-288.

WaGMAN, M. (1980). PLATO DCS: An interactive computer system for personal counseling. Journal of Counseling Psychology, 27, 16-30.

Wagman, M., \& Kerber, K. W. (1980). PLATO DCS, an interactive computer system for personal counseling: Further development and evaluation. Journal of Counseling Psychology, 27, 31-39.

Weizenbaum, J. (1966). ELIZA-A computer program for the study of natural language communication between man and machine. Communication of the Association for Computing Machinery, 9, 36-45. Weizenbaum, J. (1976). Computer power and human reason: From judgment to calculation. San Francisco: Freeman.

WHITE, R. (1959). Motivation reconsidered. The concept of competence. Psychological Review, 66, 297-323. 


\section{APPENDIX A}

Therapy with ELIZA

(In the following example, computer responses are capitalized.)

Men are all alike.

IN WHAT WAY

They're always bugging us about something or other.

CAN YOU THINK OF A SPECIFIC EXAMPLE

Well, my boyfriend made me come here.

YOUR BOYFRIEND MADE YOU COME HERE

He says I'm depressed much of the time.

I AM SORRY TO HEAR THAT YOUR ARE DEPRESSED

It's true. I am unhappy.

DO YOU THINK COMING HERE WILL HELP YOU NOT TO BE UNHAPPY

I need some help, that much seems certain.

...

Perhaps I could learn to get along with my mother.

TELL ME MORE ABOUT YOUR FAMILY

My mother takes care of me.

WHO ELSE IN YOUR FAMILY TAKES CARE OF YOU

My father.

YOUR FATHER

You are like my father in some ways.

WHAT RESEMBLANCE DO YOU SEE

You don't argue with me.

WHY DO YOU THINK I DON'T ARGUE WITH YOU

Your are afraid of me.

DOES IT PLEASE YOU TO BELIEVE I AM AFRAID OF YOU

My father is afraid of everyone.

WHAT ELSE COMES TO MIND WHEN YOU THINK OF YOUR

FATHER

Bullies.

DOES THAT HAVE ANYTHING TO DO WITH THE FACT THAT

YOUR BOYFRIEND MADE YOU COME HERE

\section{APPENDIX B \\ Therapy with PLATO DCS}

\section{Dilemma Counseling System}

This system has six major parts. The first part is a general introduction to the dilemma counseling method. The second and third parts give you practice in phrasing problems as dilemmas. The fourth and fifth parts give you practice in generating solutions to these dilemmas. The final part allows you to apply the dilemma counseling method to a problem of your own.

Select the appropriate number for the part of the Dilemma Counseling System that you wish to see.

1. Introduction

2. Dilemma Phrasing Example Problems

3. Dilemma Phrasing Practice Problems

4. Dilemma Matrix Example Problems

5. Dilemma Matrix Practice Problems

6. Your Own Problem

A final press of the NEXT key on this initial display erases the introductory material and presents a new display entitled Dilemma Phrasing Checklist. This checklist provides criteria for constructing the dilemma phrasing for various examples of practice and personal problems:

\section{Dilemma Phrasing Checklist}

1. Have you determined the central theme of the problem? That is, have you determined the two choices that must be made and the unhappy or aversive consequences for this problem?

2. Does the dilemma formulation contain two choices, i.e., choice $p$ and choice $q$ ?

3. Do the two choices result in two unhappy or aversive consequences?

4. Are the two choices and their consequences in the "if-then" and "either-or" phrasing?

5. Are any inferences that you have made about the choices or about the unhappy consequences that are present consistent with the problem as stated by the person?

For each of the dilemma phrasing example problems, the process is as follows: (a) The original wording of a problem is written on the screen, (b) a press of the NEXT key displays a poor dilemma phrasing comment below the poor dilemma phrasing, (c) a third NEXT instruction to the computer erases the poor dilemma phrasing and the instructional comment while retaining the original wording of the problem, and (e) displays a better dilemma formulation. The following is the initial display for dilemma phrasing Example Problem 1. Notice that the directive at the end of the display reminds the client that he/she can again see the dilemma phrasing checklist by simply pressing the HELP key on the PLATO DCS keyset.

\section{Example 1}

This is the way the person wrote the problem originally:

I just don't know what to do. I have to choose a major and I can't decide whether to go into business or into some branch of science. There are some good and bad things about both fields. I can make more money being a businessman but there's nothing very intellectually rewarding about it. On the other hand, a scientist does have an intellectually rewarding job, but he doesn't make very much money. So, what do I do?

A poor dilemma phrasing might be:

If I have a limited income, then I will be unhappy. And if I have limited intellectual satisfaction, then I'll also be unhappy. But either I have to have a limited income or limited intellectual satisfaction and therefore I will be unhappy.

Comment: While this is probably true as far as the subject is concerned, it doesn't take into account the choices that he is trying to make, i.e., being a scientist or businessman. Consequently, the trapped choice situation is not captured in the formulation above. The phrasing does not meet Criteria 1 and 2 in the Dilemma Phrasing Checklist.

Press HELP to see the Dilemma Phrasing Checklist.

Note-From M. Wagman, 1980. Copyright 1980 by the American Psychological Association. Reprinted by permission of the author.

\section{APPENDIX C Therapy with MORTON}

Session 1: Rapport is established between MORTON and the client. MORTON elicits information regarding the client's expectations and major complaints. It then administers the BDI (Beck Depression Inventory). The cognitive theory of emotion is explained after which the computer asks the client a series of multiple choice questions to determine if the model has been understood. Feedback on client responses is given and homework for the next session is assigned.

Session 2: The agenda for the upcoming session is set. MORTON then administers the BDI. Changes on the BDI since Ses- 
sion 1 are discussed with the ient and feedback is provided. The work of the first session is reviewed as is the client's homework. Principles of cognitive-behavioral therapy are reiterated, tested, and discussed. Homework is assigned and feedback is elicited.

Session 3: Proceeds as Session 2 except that the topic of discussion/teaching this week is dysfunctional automatic thoughts. Case examples are given. For homework the client is asked to write down specific situations that precipitate his/her feelings of depression.

Sessions 4-6: Proceed as in Sessions 2 and 3. Emphasis is on identification of automatic thoughts and of the cognitive distortions in these thoughts, and a rational response to them. In the final session guidance for termination and for dealing with future depression is given.

Note-Selmi, Klein, Greist, Johnson, \& Harris, 1982. 